\title{
Costs of Delay and Default Flight Level
}

\author{
Bc. Aneta Michlová \\ Department of Air Transport \\ Faculty of Transportation Sciences, Czech Technical \\ University in Prague \\ Prague, Czech Republic
}

\author{
Ing. Jakub Hospodka, Ph.D. \\ Department of Air Transport \\ Faculty of Transportation Sciences, Czech Technical \\ University in Prague \\ Prague, Czech Republic \\ xhospodka@fd.cvut.cz
}

\begin{abstract}
This article deals with study of costs which every single aircraft operator has to pay for its delay against schedule or for non-flying in default flight level. These costs are defined, analysed afterwards and calculated accordingly.
\end{abstract}

Keywords-strategic, tactical, reactionary costs, delay, flight level

\section{INTRODUCTION}

Today's air traffic is about 26000 aircraft movements/day over Europe region and is going to rise. It is predicted that this amount will double till 2020. European ATM costs €2-3 billion more than other world's ATM therefore our aim is reduce the difference as much as possible, moreover fulfil the future demands.[1] That is why Single European Sky project was born. Researches have been established into several stages, e.g. airspace design, new technologies, procedures, optimizing the ATM network. This thesis focuses on the ATM network performance by collecting, analysing and predicting data.

The first part of this article aims at delay costs. Since the beginning the assumption suffered from the limited view on the problem because only fuel costs were considered. However thanks to researches, studies and collecting delay data from aircraft operators it has been found out that fuel costs are a small part of total costs and we have to focus on other factors such as passenger costs.

The second part focuses on costs which are caused by changing the default flight level.

\section{COSTS OF DELAY}

\section{A. Strategic costs (Schedule padding)}

Costs which are fixed into the operational design of the network at the strategic level, based on contingencies for dealing with delays at the tactical level. Such contingencies (e.g. schedule buffers) represent an opportunity cost for the airline, as, if delays were known in advance to be reduced, these resources could be put to better use, or dispensed with to save capital.[2] Strategic costs are calculated days, weeks even months in advance by adding a buffer into schedule to absorb delays. From this point they are difficult to forecast and consequently it is difficult to show real costs caused by contingencies so that real saving are hidden to the aircraft operator. Usually the financial losses are a consequence of lack of predictability.

\section{B. Tactical costs (Delay against schedule)}

If no buffer is added into schedule, the tactical costs will increase significantly as well as reactionary costs. We have to keep in mind that the primary delay affects not only the original aircraft on subsequent legs (rotational reactionary effect) but also other aircraft (non-rotational reactionary effect) and the ratio between these delays is 88:12 which means $88 \%$ of flights was delayed by rotational reactionary delay and $12 \%$ of flight was delayed by non-rotational reactionary delay.[3]

\section{Network reactionary costs}

All delays which may be directly attributed to an initial, causal or 'primary' delay, will burden the causal aircraft, and/or others. These may decrease throughout the network until the end of the same operational day. Either all, or part, of particular flight delay durations subsequent to the primary delay may be assigned as 'reactionary' in origin.[4]

Costs are divided into 3 phases due to the difference in fuel burn in each stage; these are at-gate, taxi and en-route.

As an example, figure 1 shows the calculation of 15 minutes delay of B737-800 in 2010. We notice that during atgate phase it is assumed that engines are shut down hence no fuel is being burnt so passenger costs dominate in this phase, whilst fuel costs dominate during en-route phase. Also there is almost double difference between at-gate costs and en-route costs so it is more effective to delay the aircraft on the ground than in the air. 


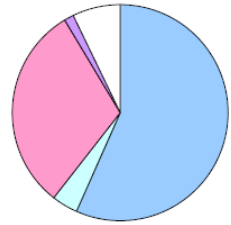

B738 at-gate (EUR 440)

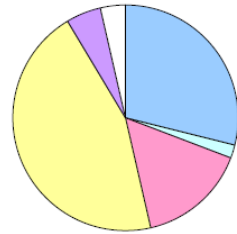

B738 en-route (EUR 860)

\begin{tabular}{|l|c|c|c|c|c|} 
Pax hard & Pax soft & Crew & Fuel & Maintenance & Reactionary \\
\hline
\end{tabular}

Figure 1. Costs in 2010 Euros. Delay weights use 2009 ATFM data

Pax hard cost means costs for rebooking, compensation or care while the flight is delayed, on the other hand soft cost is cost due to revenue loss such as passenger having a flexible ticket and taking competitor's on-time flight instead of a delayed flight.

The total cost of ATFM delay in 2010 was $€ 1250$ million (all causes considered), 92\% of flights did not incur ATFM delay, the average cost of delayed flight was $€ 1660$, the average value calculated as a division of total ATFM delay cost and total ATFM minutes is $€ 81 / \mathrm{min}$.[5]

\section{DEFAULT FLIGHT LEVEL}

The most efficient flight level for every aircraft considering fuel consumption is an optimal flight level, however, only occasionally ATC allows the airplane to fly in optimal flight level and it is done only if there is a spare traffic in the airspace e.g. at night. The airplane flies in its noneconomical flight level most of the time. But what if the flight level is changing during the whole flight? Theoretically the heavier the airplane is, the more fuel it consumes. The more fuel the airplane consumes during the flight, the higher the optimal flight level is. If we want to fly as economically as possible, we will continually increase our flight level. Unfortunately it is not possible during normal day-to-day operation. Let's focus on the usual case.

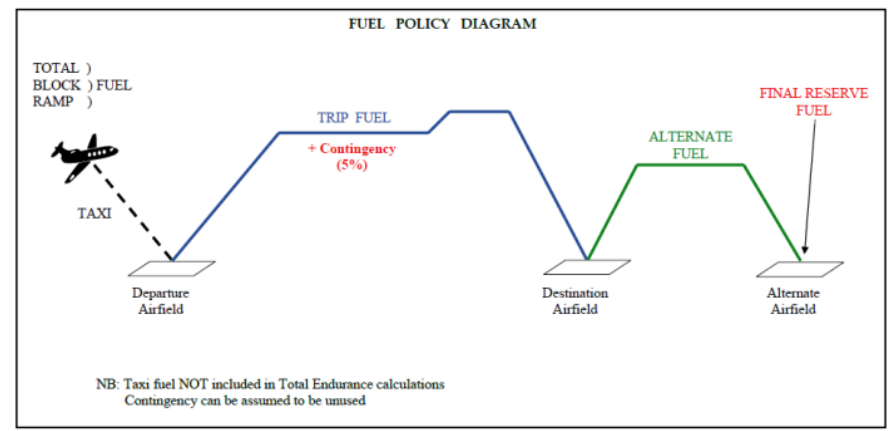

Figure 2. EASA Fuel policy

Figure 2 shows how much fuel you have to consider for a flight and what the minimum for a flight is, this is known as a Fuel policy by EASA.

\section{COSTS' ANALYSIS AND ESTIMATION}

\section{A. Effects of delay}

Figure 3 shows how the aircraft operator manages the delay effects.

\section{1) Strategic, gate-to-gate level}

Based on statistical consideration from the previous season aircraft operator sets up the individual legs including buffers large enough to absorb delay caused by contingencies and small enough not to block the resources.

\section{2) Strategic, network level}

Then taking acount the individual requirements of each leg a network schedule is set up. As the white arrow shows the process must be repeated constantly in order to optimize the schedule.

\section{3) Tactical, gate-to-gate level}

If the strategic delay was counted properly, the primary delay caused at the day of operation would be absorbed by buffers and would not lead to other delay normally.

\section{4) Tactical, network level}

However due to contingencies in this case ATFM restrictions reactionary delays has been created. Buffers are not designed to absorb other delay than primary and therefore we have to take in account that the aircraft doesn't recover from the first delay of the day.

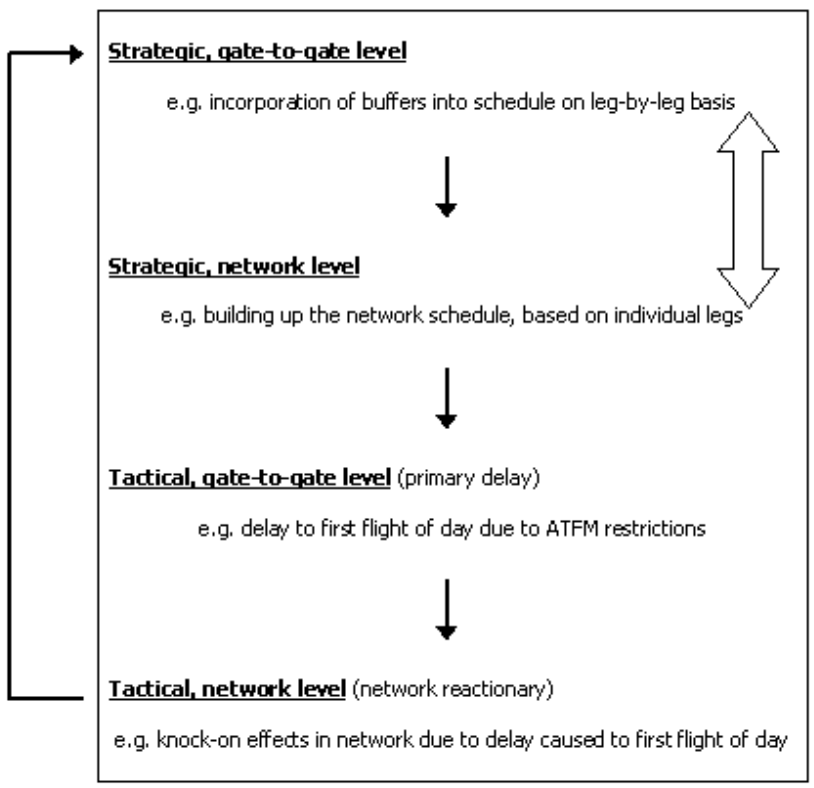

Figure 3. Hierarchy of delay level costs

\section{B. Primary and reactionary delay comparison}

Primary and secondary causes vary according to airport and area. Regular division of delay causes and 2011/2012 statistics are shown in figure 4. 


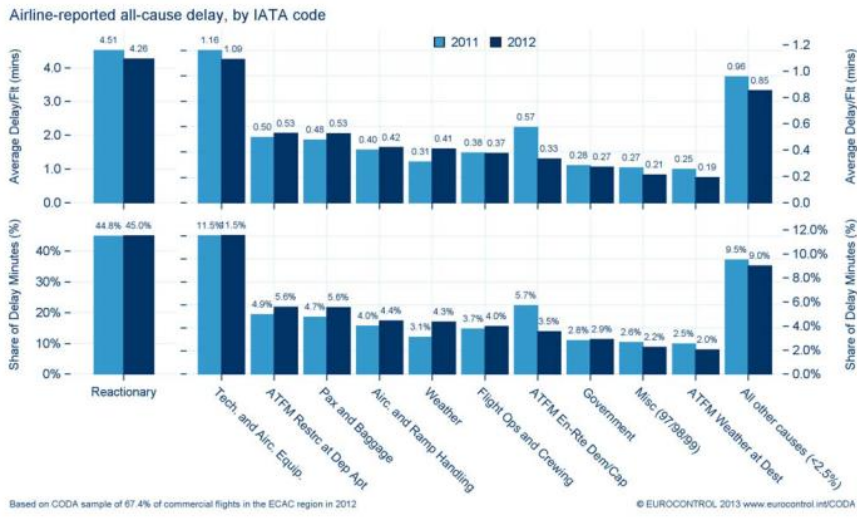

Figure 4. Primary and reactionary all-cause delay in 2011 and 2012, by causes

\section{2013 DELAY STATISTICS}

TABLE I. Average delay due to air traffic flow in year 2013[6]

\begin{tabular}{|c|c|c|c|c|c|c|c|}
\hline $\begin{array}{l}\text { ARPORT } \\
\text { NAME }\end{array}$ & $\begin{array}{l}\text { AIRPORT } \\
\text { ID }\end{array}$ & $\begin{array}{l}\text { DAllY YAVG } \\
\text { TRAFIC } \\
\text { (Dep+ATr) }\end{array}$ & $\begin{array}{l}\text { \% DEP } \\
\text { REGUATED } \\
\text { TRAFFIC }\end{array}$ & $\begin{array}{l}\text { AVG DELAY PER } \\
\text { DEP REGULAATED } \\
\text { FUGHT }\end{array}$ & $\begin{array}{l}\text { \% EARLY } \\
\text { DEP TRAFFIC } \\
\text { OUTSIDE STW }\end{array}$ & $\begin{array}{l}\text { \% DEP } \\
\text { IRAFFC } \\
\text { INSIDE STW }\end{array}$ & $\begin{array}{l}\text { \%) LATE } \\
\text { DEP RRAFIC } \\
\text { OUTSIDE STW }\end{array}$ \\
\hline BIRMINGHAM & EGBB & 251 & $10.2 \%$ & $129 \mathrm{~min}$ & $16.8 \%$ & $77.6 \%$ & $5.6 \%$ \\
\hline OTOPENANTLL. & LROP & 240 & $9 \%$ & $102 \mathrm{~min}$ & $5.1 \%$ & $90.8 \%$ & $4.1 \%$ \\
\hline FERHEGY-EUDAPEST & LHGP & 229 & $11.3 \%$ & $11.3 \mathrm{~min}$ & $3 \%$ & $93.4 \%$ & $3.6 \%$ \\
\hline VENEZA TESSERA & UPZ2 & 222 & $13 \%$ & $10 \mathrm{~min}$ & $7.5 \%$ & $89.3 \%$ & $32 \%$ \\
\hline STAVANGERYSOLA & ENZV & 216 & $6 \%$ & $125 \min$ & $1.4 \%$ & $96.1 \%$ & $25 \%$ \\
\hline GLASGOW & EGPF & 213 & $7.3 \%$ & $14.7 \mathrm{~min}$ & $5.6 \%$ & $89.4 \%$ & $5 \%$ \\
\hline LONDONCITY & EGLC & 202 & $7.2 \%$ & $128 \min$ & $9 \%$ & $87.4 \%$ & $3.6 \%$ \\
\hline EALE-MULHOUSE & $\angle F S B$ & 199 & $11.5 \%$ & $11.5 \mathrm{~min}$ & $8.2 \%$ & $852 \%$ & $6.6 \%$ \\
\hline IZMR-ADNAN-MENDERES & LTQM & 196 & $4.5 \%$ & $8.7 \mathrm{~min}$ & $18.8 \%$ & $69.8 \%$ & $11.4 \%$ \\
\hline BERGAMOIORIO ALSERIO & LIME & 195 & $6.7 \%$ & $10.1 \mathrm{~min}$ & $4.4 \%$ & $925 \%$ & $3.1 \%$ \\
\hline ABERDEEN & EGPD & 194 & $5.4 \%$ & $169 \mathrm{~min}$ & $8.5 \%$ & $86.6 \%$ & $4.9 \%$ \\
\hline ALICANTE & LEAL & 186 & $18.8 \%$ & $11.9 \min$ & $22 \%$ & $95.4 \%$ & $25 \%$ \\
\hline RIGAINTL & EVRA & 184 & $5.9 \%$ & $10 \mathrm{~min}$ & $5.1 \%$ & $87.9 \%$ & $7 \%$ \\
\hline EAST MIDLANDS & EGNX & 181 & $7.2 \%$ & $121 \mathrm{~min}$ & $14.2 \%$ & $81.1 \%$ & $4.7 \%$ \\
\hline BOLOGNA & LIPE & 178 & $10.3 \%$ & $124 \min$ & $5.7 \%$ & $92.6 \%$ & $1.7 \%$ \\
\hline HANNOVER LANGENHAGEN & EDOV & 175 & $122 \%$ & $107 \mathrm{~min}$ & $2.3 \%$ & $93.1 \%$ & $4.6 \%$ \\
\hline SCHOENEFELD-EERUIN & EDOB & 173 & $10.7 \%$ & $10.9 \mathrm{~min}$ & $5.4 \%$ & $89.9 \%$ & $4.7 \%$ \\
\hline GOTEBORGLANDVETTER & ESGG & 166 & $10.6 \%$ & $11.9 \min$ & $7.1 \%$ & $91.1 \%$ & $1.8 \%$ \\
\hline PORTO & $\begin{array}{ll}\text { LPPR } \\
\end{array}$ & 163 & $9.6 \%$ & $11.6 \min$ & $5.7 \%$ & $887 \%$ & $5.6 \%$ \\
\hline LEIPZIGHALEE & EDDP & 163 & $6 \%$ & $114 \mathrm{~min}$ & $1.9 \%$ & $957 \%$ & $24 \%$ \\
\hline LUXEMBOUFG & ELX & 158 & $124 \%$ & $125 \mathrm{~min}$ & $10.6 \%$ & $83.1 \%$ & $6.3 \%$ \\
\hline BRISTOULULSGATE & $E G G D$ & 159 & $10.2 \%$ & $13.8 \mathrm{~min}$ & $21.6 \%$ & $752 \%$ & $3.1 \%$ \\
\hline TRONOHEIMVAERNES & ENAA & 155 & $5.7 \%$ & $13.5 \mathrm{~min}$ & $1.9 \%$ & $95.7 \%$ & $24 \%$ \\
\hline BOFOEAUX-MENGGNAC & LFEO & 155 & $6.7 \%$ & $126 \mathrm{~min}$ & $7 \%$ & $87.7 \%$ & $5.2 \%$ \\
\hline NAPOU CAPOCICHINO & LIFN & 153 & $6.2 \%$ & $112 \mathrm{~min}$ & $3.6 \%$ & $94.6 \%$ & $1.8 \%$ \\
\hline CATANIA FONTANAROSSA & LCC & 152 & $3.7 \%$ & $12 \min$ & $9.8 \%$ & $84.2 \%$ & $5.9 \%$ \\
\hline TENERIFE SUR & $\begin{array}{l}\text { GCTS } \\
\text { s }\end{array}$ & 74 & $13.4 \%$ & $11.7 \min$ & $5.3 \%$ & $86.5 \%$ & $82 \%$ \\
\hline PARIS LE BOURGET & LFPE & 147 & $7.7 \%$ & $17.1 \mathrm{~min}$ & $3.3 \%$ & $89.1 \%$ & $7.6 \%$ \\
\hline IEIZA & LEIB & 147 & $14.5 \%$ & $137 \mathrm{~mm}$ & $1.8 \%$ & $95.9 \%$ & $23 \%$ \\
\hline NUERNGERG & EDON & 142 & $12 \%$ & $126 \min$ & $6 \%$ & $922 \%$ & $1.9 \%$ \\
\hline ROMA CIAMPINO & LIFA & 141 & $6.6 \%$ & $10.1 \mathrm{~min}$ & $9.6 \%$ & $79.7 \%$ & $10.8 \%$ \\
\hline NANTES & LFRS & 138 & $8.1 \%$ & $142 \mathrm{~min}$ & $11.7 \%$ & $85.7 \%$ & $2.6 \%$ \\
\hline CHARLEROUBRUSSELS SOUTH & EBCI & 197 & $8.6 \%$ & $11.9 \mathrm{~min}$ & $4.2 \%$ & $88.9 \%$ & $7 \%$ \\
\hline STOCKHOLMEROMMA & ESSB & 137 & $1.3 \%$ & $9.8 \mathrm{~min}$ & $24 \%$ & $89 \%$ & $8.5 \%$ \\
\hline VALENCIA & LEVC & 134 & $10.7 \%$ & $11.5 \mathrm{~min}$ & $1.2 \%$ & $97.4 \%$ & $1.5 \%$ \\
\hline IFAKLONNNIKOS KAZANTZAKII & LGIR & 128 & $7.9 \%$ & $129 \min$ & $9.1 \%$ & $77.3 \%$ & $13.6 \%$ \\
\hline NEWCASTLE & EGNT & 128 & $11.5 \%$ & $124 \min$ & $4.6 \%$ & $90 \%$ & $5.4 \%$ \\
\hline TENERIFE NORTE & Gcxo & 63 & $4.9 \%$ & $11.3 \mathrm{~min}$ & $3.2 \%$ & $94 \%$ & $29 \%$ \\
\hline ARRECIFE LANZAROTE & GCRR & 59 & $9.6 \%$ & $13.8 \mathrm{~min}$ & $1.6 \%$ & $95.1 \%$ & $3.3 \%$ \\
\hline FARO & \begin{tabular}{ll|l} 
LDFR \\
\end{tabular} & 118 & $11.6 \%$ & $13.6 \min$ & $9.5 \%$ & $88 \%$ & $25 \%$ \\
\hline THESSALONIKWWAKEDONIA & LGTS & 117 & $5.1 \%$ & $11.1 \mathrm{~min}$ & $9.3 \%$ & $772 \%$ & $13.5 \%$ \\
\hline BILUND & EKBI & 115 & $112 \%$ & $11.9 \mathrm{~min}$ & $4.2 \%$ & $91.7 \%$ & $4.1 \%$ \\
\hline PISA SAN GIUSTO & LIRP & 113 & $8.7 \%$ & $10.7 \mathrm{~min}$ & $11.9 \%$ & $78.8 \%$ & $9.4 \%$ \\
\hline JERSEY & Eaw & 113 & $1.8 \%$ & $21.1 \mathrm{~min}$ & $2 \%$ & $95.5 \%$ & $25 \%$ \\
\hline GUERNSEY & EGUB & 113 & $1.2 \%$ & $17.6 \mathrm{~min}$ & $7.5 \%$ & $82 \%$ & $10.5 \%$ \\
\hline KRAKOWEALICE & EPKK & 112 & $10.5 \%$ & $119 \min$ & $4.8 \%$ & $87 \%$ & $82 \%$ \\
\hline PALERYO PUNTA RAISI & LIOS & 112 & $3.9 \%$ & $124 \min$ & $3.7 \%$ & $93.8 \%$ & $25 \%$ \\
\hline LARNACA & LOCK & 111 & $13.3 \%$ & $10.6 \mathrm{~min}$ & $5.9 \%$ & $867 \%$ & $7.4 \%$ \\
\hline 8000 & ENSO & 110 & $1.4 \%$ & $182 \min$ & $2.5 \%$ & $94.7 \%$ & $28 \%$ \\
\hline
\end{tabular}

For better idea how important problem is delay we show average delay statistics from chosen European airports, in table I. Table I. covers statistics for whole year 2013. Early departing traffic is traffic departing 5 minutes or more prior slot time, late departing traffic is traffic departing later than 10 minutes after original slot time. \% of regulated traffic is percentage (compared with the ATC Activated Traffic count) of terminated flights affected by one or more regulations. Only the Regulated Flights for which an Actual Take-Off is known are used.

If we used early mentioned sum of $81 € /$ minute of delay costs we may estimate that according to numbers in figure 5 costs of delay originated by air traffic flow only in Prague Airport 2013 is more than 7,4 million EUR.

\section{CONCLUSION}

Costs of delay cause a financial losses, therefore, prevention and recovery process have to be established. We usually focus on the tactical phase but the truth is that we should focus on the strategic phase, this planning can reduce delays. Despite of all known values we cannot avoid delay. However, we can soften the impact of delay by calculating the delay in advance - strategic delay, by adding buffer into schedule to absorb delay caused by contingency. Nevertheless there is a risk of blocking the aircraft and resource due to larger buffer than the situation needs which affect the airline profitability as well. The aircraft operator has to calculate and predict the schedule very properly but even in this case we are not able to avoid a coincidence. If the primary delay occurs earlier in the day, it will cause the greater reactionary delay. This is what the aircraft operator should do primarily. As it was mentioned at the beginning airline is not the only one, a huge work should be made also on the other side - ATM, route planners, airspace designers, airports - to make the flow smoother.

\section{REFERENCES}

[1] A. Cook, G. Tanner and S. Anderson, "Evaluating the true cost to airliner of one minute of airborne or ground delay", University of Westminster, London, pp. 17-19, May 2004

[2] A. Cook, G. Tanner and S. Anderson, "Evaluating the true cost to airliner of one minute of airborne or ground delay", University of Westminster, London, pp. 19, May 2004

[3] A. Cook, G. Tanner and S. Anderson, "European airline delay cost reference values", University of Westminster, London, pp. 4, March 2011.

[4] A. Cook, G. Tanner and S. Anderson, "Evaluating the true cost to airliner of one minute of airborne or ground delay", University of Westminster, London, pp. 17, May 2004

[5] A. Cook, G. Tanner and S. Anderson, "European airline delay cos reference values", University of Westminster, London, pp. 8, March 2011.

[6] NM ATFCM Monthly Summary per Airport (Traffic Part) - December 2013

This article was prepared with help of informations provided by EUROCONTROL NM ATFCM. 